\title{
Early Detection and Rapid Response (EDRR) to Nonnative Wildlife in South Florida
}

\section{What is EDRR?}

EARly Detection And RAPID Response (EDRR) is the capability to both detect and respond to nonnative wildlife soon after they arrive at a location. It is not always possible to prevent introduction or establishment of nonnative wildlife, or to predict which species will become invasive over time (Westbrooks et al. 2011). When prevention of new introductions fails, EDRR increases the likelihood that invasions will be successfully contained or eradicated while populations are still small and localized.

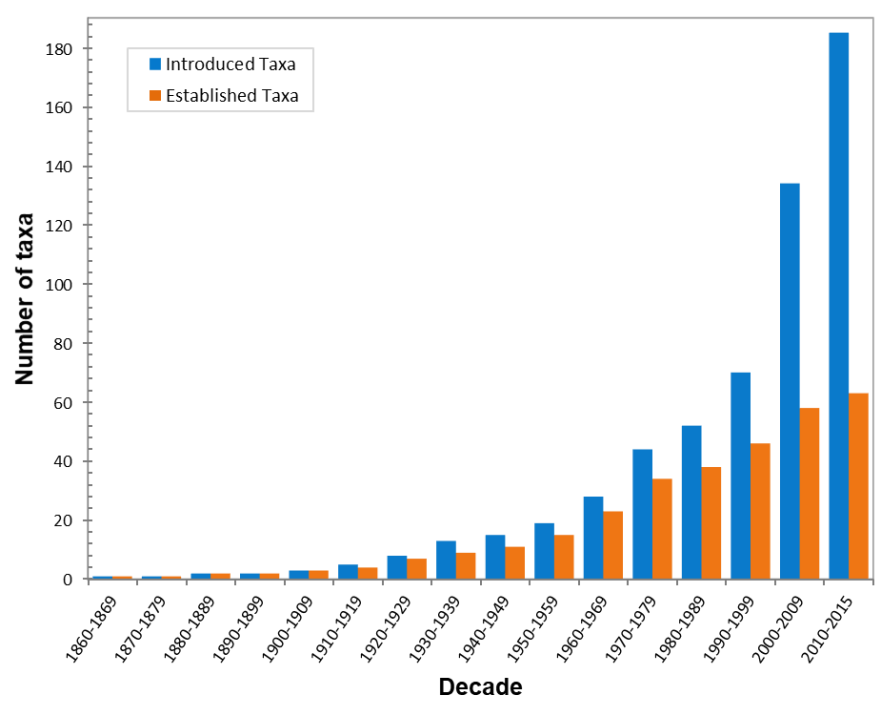

Figure 1. Accumulation of total introduced $(n=185)$ and established $(n=63)$ nonnative amphibians and reptiles in Florida by decade from 1863 through 2015 (Adapted from Krysko et al. 2016).

\section{Why do we need EDRR?}

Invasive nonnative wildlife threaten successful restoration of Everglades ecosystems in south Florida, and the number of introductions shows no sign of abating (National Research Council 2005; Figure 1). The Comprehensive Everglades Restoration Plan (CERP) is one of the most ambitious ecosystem restoration projects ever conceived (National Research Council 2008). In order to fully support the broad CERP goal of enhancing ecological values and improving native species abundance, invasive wildlife must be controlled.

Introduced species frequently become established before their presence is known, at which point options for management become limited and expensive and are often ineffective (Figure 2). To protect vulnerable natural resources, it is imperative to respond quickly to emerging threats while they remain localized. When prevention fails, EDRR is the most cost-effective method for dealing with invasive wildlife. More than 60 species of reptiles and amphibians are already breeding in Florida (Figure 1). The next "Burmese python" may already be present.

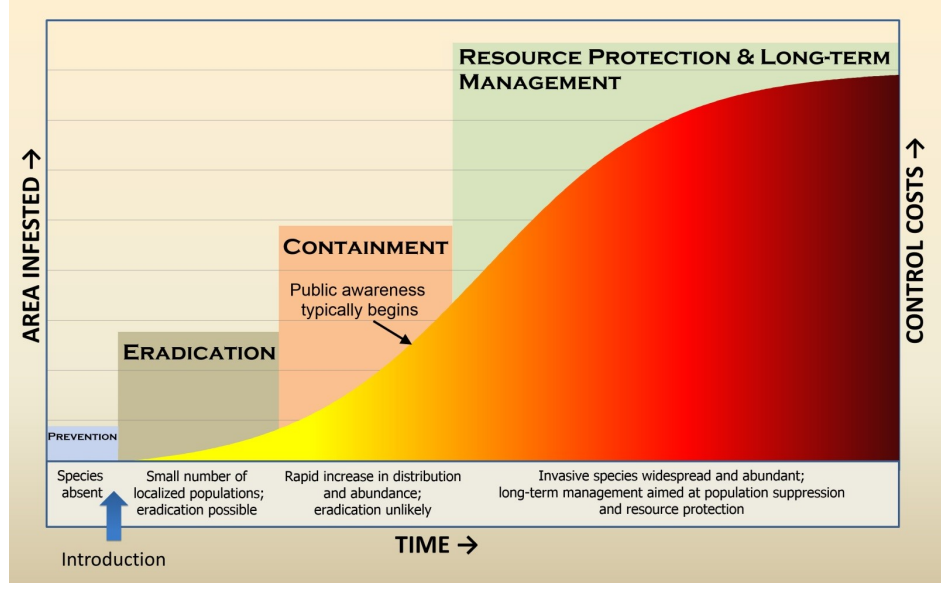

Figure 2. The Invasion Curve, adapted from the Invasive Plants and Animals Policy Framework, State of Victoria, Department of Primary Industries, 2010.

\section{How does EDRR work?}

The following components are characteristic of an operational framework for regional EDRR programs:

1) Active (deliberate surveys) and passive (as part of another effort) observation networks

2) Reporting system

3) Trained response capability

4) Monitoring and evaluation capability

EDRR occurs as a series of sequential steps, although sometimes steps can occur so rapidly as to seem simultaneous (Figure 3 ). Observation of a questionable species is the first step, followed by identification as native or nonnative. The steps thereafter are determined by a threat assessment of the species in question. If action is required, rapid and thorough monitoring are necessary to determine the extent of the threat and eliminate it if possible.

\section{Implementing EDRR}

Establishing an active EDRR system for nonnative wildlife responds to Goal 2: Eradicate Invasive Exotic Species by Implementing Early Detection and Rapid Response of the Invasive Exotic Species Strategic Action Framework (Framework) developed by the South Florida Ecosystem Restoration Task Force (SFERTF 2015). The Framework recommends that EDRR begin before invasive species are identified in the ecosystem with the following objectives:

Preparation AND monitoring to enhance early detection. It is not possible to look everywhere for every species; therefore the most vulnerable areas should be prioritized based on risk assessments by species and by geographic area. Within the Framework, preparation for EDRR includes establishing interagency partnerships, securing access to public lands, and obtaining permits and funding.

ASSESSMENT (SCREENING) once a newly detected species is identified.

RAPID RESPONSE (ACTION) to identified threats. 


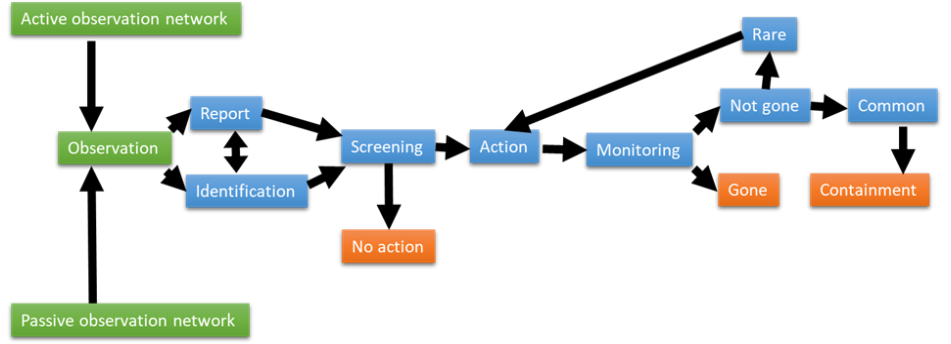

Figure 3. Conceptual model of a simplified approach to EDRR. Observation of a questionable species is the first step, followed by identification as native or nonnative. The steps thereafter are determined by a threat assessment of the species in question.

\section{Effectiveness/Success stories}

There are a number of examples of EDRR successes from across the country (The U.S. Department of the Interior 2016). In south Florida, a hotspot for invasions, interagency efforts have effectively prevented new invasions and expansion of already-established invasive species.

One of the first EDRR cases in south Florida was the sacred ibis (Threskiornis aethiopicus), which escaped from captivity during Hurricane Andrew in 1992. Through collaborative observational networks and funding from the Everglades Foundation, USDA Wildlife Services, and Zoo Miami, the sacred ibis was successfully controlled while populations remained localized and extirpation was still feasible, reducing threats to native wading birds and endangered wetland species (Figure 4).

Reports received through word-of-mouth communication and through the South Florida Water Management District's python removal program have led to probable extirpations of veiled chameleons (Chamaeleo calyptratus) from a natural area near Arthur R. Marshall Loxahatchee National Wildlife Refuge and panther chameleons (Furcifer pardalis) from a natural area in Broward County by the University of Florida (UF) and the Florida Fish and Wildlife Conservation Commission (FWC) (Rochford et al. 2013). An interagency effort by UF and FWC also led to the removal of a Nile crocodile from Everglades National Park (Figure 5).
Arguably, one of the most important components of EDRR in south Florida is the IveGot1 reporting network. Anyone can call in invasive species sightings to the phone hotline (1-888-IVEGOT1), report on the web at IveGot1.org, or report through the IveGot1 smartphone applications. Reports are then uploaded to EDDMapS (Early Detection and Distribution Mapping System), where invasive species occurrences can be tracked using electronic early detection reporting tools.

A recent noteworthy success following an IveGot1 hotline report was the swift removal of a female water monitor (Varanus salvator) with 14 eggs from Miami-Dade County by the FWC. This removal may have prevented the potential establishment of a new nonnative species. Furthermore, a call in 2017 to the IveGot1 hotline led to the FWC removal of an Argentine black and white tegu (Salvator merianae) from Key Largo, a new area for this already-established invasive species.

The FWC and U.S. Geological Survey have applied EDRR to eradicate nonnative fish including carnivorous redbelly piranha (Pygocentrus nattereri) from a pond in Palm Beach County, and most recently, bay snook (Petenia splendida) from Pinecrest Gardens in MiamiDade County. Each of these examples demonstrates the need for persistent monitoring and rapid response to new and emerging threats.

Furthermore, EDRR has been integrated into localized initiatives, such as the Everglades Invasive Reptile and Amphibian Monitoring Program (EIRAMP), where active and opportunistic wildlife surveys are regularly conducted. As a result, a trained response team has removed more than 3,000 nonnative and invasive animals from the Everglades and has likely prevented new populations from establishing.

\section{Implications}

There is an urgent need to prevent additional costs and damages from invasive wildlife to Everglades restoration. EDRR is the best option to identify early and attempt to eradicate new introductions and save avoidable costs, time, and valuable natural resources. Existing EDRR programs in south Florida and elsewhere have proven effective, yet due to the dynamic threat of biological invasions, speed and adaptability are crucial for continued success.

\section{References}

Krysko, K. L. et al. 2016. "New verified nonindigenous amphibians and reptiles in Florida through 2015, with a summary of over 152 years of introductions." IRCF Reptiles \& Amphibians 23(2):110-143.

National Research Council, 2008. Progress Toward Restoring the Everglades: The Second Biennial Review-2008. National Academies Press.

National Research Council. 2005. Re-Engineering Storage in the Everglades: Risks and Opportunities. National Academies Press. Washington. DC.

Rochford, M. R. et al. 2013. “The panther chameleon, Furcifer pardalis (Cuvier 1829) (Chamaeleonidae), another introduced chameleon species in Florida.” IRCF Reptiles \& Amphibians 20(4):205-207.

South Florida Ecosystem Restoration Task Force (SFERTF). 2015. Invasive Exotic Species Strategic Action Framework.

The U.S. Department of the Interior. 2016. Safeguarding America's lands and waters from invasive species: A national framework for early detection and rapid response, Washington D.C., 55p.

Westbrooks, R. G. and R. E. Eplee. "Early detection and rapid response.” 2011. In Simberloff, D. \& M. Rejmanek (eds), Encyclopedia of Biological Invasions. University of California, Berkeley, CA: 169-177.

\section{Authors}

Justin R. Dalaba and Frank J. Mazzotti University of Florida Fort Lauderdale Research \& Education Center justindalaba@ufl.edu,fjma@ufl.edu

\section{UI $\mid$ IFAS Extension}

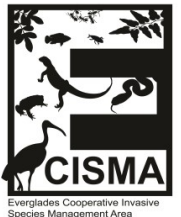

An Equal Opportunity Institution. UF/IFAS Extension, University of Florida, Institute of Food and Agricultural Sciences, Nick T. Place, dean for UF/IFAS Extension. Single copies of UF/IFAS Extension publications (excluding 4-H and youth publications) are available free to Florida residents from county UF/IFAS Extension offices. 